\title{
Quadrupedal movement training improves markers of cognition and joint repositioning
}

Martyn J Matthews ${ }^{1}$, Mohamed Yusuf, Caron Doyle, and Catherine Thompson School of Health Sciences, University of Salford, Salford, UK, M6 6PU

\begin{abstract}
Introduction - Exercise, and in particular balance and coordination related activities such as dance, appear to have positive effects on cognitive function, as well as neurodegenerative conditions such as dementia and Parkinson's disease. Quadrupedal gait training is a movement system requiring coordination of all four limbs that has previously been associated with cognitive development in children. There is currently little research into the effect of complex QDP movements on cognitive function in adults.
\end{abstract}

Purpose - To determine the effects of a novel four-week quadrupedal gait training programme on markers of cognitive function and joint reposition sense in healthy adults.

Methods - Twenty-two physically active sports science students (15 male and 7 female) were divided into two groups: a training group (TG) and a control group (CG). All participants completed the Wisconsin Card Sorting Task (WCST) and were tested for joint reposition sense before and after a four-week intervention, during which time the TG completed a series of progressive and challenging quadrupedal movement training sessions.

Results - Participants in the TG showed significant improvements in the WCST, with improvements in perseverative errors, non-perseverative errors, and conceptual level response. This improvement was not found in the CG. Joint reposition sense also improved for the TG, but only at 20 degrees of shoulder flexion.

\footnotetext{
${ }^{1}$ Corresponding Author (m.j.matthews@ @alford.ac.uk)
} 
Conclusions - Performance of a novel, progressive, and challenging task, requiring the coordination of all 4 limbs, has a beneficial impact on cognitive flexibility, and in joint reposition sense, although only at the specific joint angle directly targeted by the training. The findings are consistent with other studies showing improvements in executive function and joint reposition sense following physical activity.

\section{Introduction}

There is a growing body of research supporting the role of physical activity in improving the quality and longevity of human life. Improvements have been found in areas such as innate immunity and a decrease in vascular inflammation (Ford, 2002; Gleeson et al., 1995; Hoffinan- Goetz, 1998;

Venkatraman \& Fernandes, 1997; Woods, Vieira, \& Keylock, 2009), as well as autonomy and independence in the elderly (Lamb, Jørstad- Stein, Hauer, \& Becker, 2005; Pahor, 2006). Recent evidence also suggests that physical activity (especially aerobic exercise) may have a positive impact on cognition (Hillman et al., 2006), attenuate age related cognitive decline (Hamer \& Chider, 2009; Paillard, 2015), and reduce the risk of Alzheimer's disease and dementia (Buchman et al., 2012; Daly, McMinn, \& Allan, 2015; Voelcker-Rehage \& Niemann, 2013;). More specifically, in cognitive tasks such as reasoning, working memory, and vigilance, performance of populations that exercise regularly exceeds those that do not engage in regular exercise (Bunce, Barrowclough, \& Morris, 1996; Cook, Albert, Berkman, Blazer, Taylor, \& Hennekens, 1995; Erikson et al., 2011).

Likely mechanisms for the association between cardiovascular physical activity and improved cognitive performance include increased cerebral blood flow, particularly to frontal and parietal regions (Colcombe et al., 2004), changes in neurotransmitter release, structural changes in the central nervous system, and altered arousal levels (Gligoroska \& Manchevska, 2012). Exercise 
programs have also been associated with changes in central markers of improved brain function, such as brain derived neurotrophic factor (Voss, Kramer, Basak. Prakesh, \& Roberts, 2010).

Balance and coordination related activities such as dance, also appear to have positive effects on measures of cognitive wellbeing as well as neurodegenerative conditions such as dementia and Parkinson's Disease (Ahlskog, Geda, Graff-Radford, \& Peterson, 2011; Firth, Cotter, Elliott, French, \& Yung, 2015; Hamer \& Chida, 2009; Hui, Chui, \& Woo, 2009; Kattenstroth, Kalisch, Holt, Tegenthoff, \& Dinse, 2013; Kullberg-Turtiainen, 2012; Ravelin, Isola, \& Kylmä, 2013; Scherder, Bogen, Eggermont, Hamers, \& Swaab, 2010; Sehm, Weinstein, Ghent, Meyer, \& Teuber, 2014; Tanaka, de Quadros, Sanots, Stella, Gobbi, \& Gobbi, 2009). For instance, patients show more efficient patterns of brain activity, especially in frontal and parietal cortical areas, related to motor control and learning, following coordinative activity (Monno, Temprado, Zanone, \& Laurent, 2002; Voelcker-Rehage \& Niemann, 2013). It is likely that the perceptual demands and attention required to coordinate these complex movements (as opposed to the more repetitive and automated movements typical of aerobic exercise) stimulate adaptations to information processing that improve both attention and the ability to process visual and spatial information (Monno et al., 2002; Voelcker-Rehage \& Niemann, 2013).

The changes induced by coordinative exercise appear different to, and independent of those induced by cardiovascular activity, and are similar to those found following exposure to enriched and stimulating environments for elderly or untrained individuals (Voelcker-Rehage, Godde, \& Staudinger, 2011; Kattenstroth et al., 2013). Dance, in particular, in addition to its purely physical challenges such as balance and physical activity, involves rhythmic motor coordination, emotions, social interaction, and acoustic stimulation (Kattenstroth et al., 2013). Yet even the performance of automated exercise such as walking can provide sufficient coordination challenges to induce these changes (Voelcker-Rehage \& Niemann, 2013). Coordinative activity, specifically the learning of complex whole body tasks such as balancing and juggling, has also been associated with increased 
grey matter volume in the frontal and parietal regions (Draganski, Gaser, Busch, Schuierer, Bogdahn, \& May, 2004; Taubert et al., 2010). These regions are associated with cognitive functions such as attentional selection, task switching, inhibitory control, and working memory (Casey et al., 2000; Kim, Cilles, Johnson, \& Gold, 2012; Lie, Specht, Marshall, \& Fink, 2006).

There also appears to be a relationship between early motor development (particularly in gross motor skills) and later cognitive function in aspects such as working memory and processing speed (Piek, Dawson, Smith, \& Gasson, 2008). In particular, quadrupedal (QDP) gait movement, a form of locomotion used by most quadrupeds and human infants when crawling (Kondo, 1985), not only benefits joint reposition sense and coordination, but is also linked to the rehabilitation of patients with movement disorders (Dietz, 2011) and cognitive improvements observed in developing children (Herbert, Gross, \& Hayne, 2007; Patrick, Noah, \& Yang, 2009; Shah et al., 2013). As crawling is one of the first movements that cognitively challenges an infant, it is argued to be a contributor to a child's cognitive development (Bell \& Fox, 1996; Herbert et al., 2007) with an association observed between the onset of crawling and the appearance of cortical organisation (Bell \& Fox, 1996). Research also shows that crawling aids early motor control development such as eyehand coordination, proprioception, tactile input, and spatial awareness (Clearfield, 2004; Herbert et al., 2007; Mcewan, Dihoff, \& Brosvic, 1991). For example, hands-and-knees crawlers exhibit more improvements in these areas than belly crawlers (Freedland \& Bertenthal, 1994; Kermoian \& Campos, 1988). This bilateral coordination requires two opposite limbs to move simultaneously, and appears to drive cognitive development in infants by stimulating cortical organisation, particularly during the more novel, or unfamiliar, stages of the task (Bell \& Fox 1996). Nuernberger, Rogers, \& Mckenna (2010) speculated that exercises requiring coordination across the midline stimulate the brain to organise itself, forcing both hemispheres of the brain to communicate with to each other. Although there is a clear link between QDP and cognitive development in children, there is little research into the effect of complex QDP movements on cognitive function in adults. There exists, 
however, a growing body of research highlighting the positive effects of other complex movements, such as dancing, on cognition in general and in slowing cognitive decline (Hui et al., 2009; KullbergTurtiainen, 2012; Ravelin et al., 2013; Verghese et al., 2003). It is possible, therefore, that a complex and novel exercise that requires the coordination of all four limbs, may have similar benefits to other complex movements.

Studies that investigate the importance of physical activity on cognitive ability show that engaging in exercise can have a positive impact on a range of cognitive functions. For example, Hillman et al. (2006) found that individuals who reported participating in more exercise were better able to inhibit task-irrelevant information in a flanker task, and McAuliffe (2004) found that athletes can maintain a top-down attentional set more effectively in a spatial cuing task than non-athletes. A review by Mann, Williams, Ward, and Janelle (2007) also concludes that increased expertise in sport is associated with improved visual search (requiring selective visual attention; the ability to identify and focus on task-relevant information, and inhibit task-irrelevant information). Whilst these findings show improvements across different cognitive abilities, they all fall under the category of 'executive functions' (Hillman, Erickson, \& Kramer, 2008). This is supported by meta-analyses showing that taking part in physical activity has specific benefits on executive control (Colcombe \& Kramer, 2003; Voss, et al., 2010).

Executive functions allow an individual to allocate cognitive resources on the basis of task demands; focusing on relevant information and ignoring irrelevant information. They develop during adolescence and are critical in supporting the intentional allocation of cognitive resources (Anderson, 2008). Diamond (2013) summarises three key executive functions; inhibition, cognitive flexibility, and working memory. Working memory enables an individual to hold information in their mind and manipulate it (link it to new incoming information and existing knowledge from long-term memory), flexibility relates to the ability to adapt to changing circumstances, and inhibition allows an individual to focus on a task and ignore distracting information. Improved executive function (also 
termed executive control or cognitive control; Diamond, 2013) is associated with better concentration and performance in a task, which then has an impact on physical and emotional wellbeing.

Daly, et al. (2015) have given a clear explanation of why physical activity can support executive function (and vice versa) by mapping the key aspects of exercise onto the core executive functions. They propose that the goal of taking part in physical activity is intentional, it requires planning, focus, careful monitoring of performance, and inhibition of any competing activities. This is supported by research showing that individuals who perform better on tests of executive control are more likely to engage in regular exercise (e.g., McAuley et al., 2011). Furthermore, impairments in executive control are associated with damage to the pre-frontal cortex (e.g., Owen, Roberts, Hodges, Summers, Polkey, \& Robbins, 1993), an area also implicated in the relationship between exercise and cognition (e.g., Hillman et al., 2008).

Improved executive functioning is linked to increased activity in the frontal lobe and this is one area of the brain that continues to develop beyond puberty (e.g. Zalazo, Craik, \& Booth, 2004). Consequently, engaging in activities designed to facilitate executive functioning could have longlasting benefits to cognitive ability. Findings support this suggestion, showing that cognitive plasticity is possible in older adults following training in tasks designed to test attentional control (Bherer, Kramer, Peterson, Colcombe, Erickson, \& Becic, 2006).

Given the evidence for a relationship between increased physical activity and improvements in executive functioning the current study measured the impact of QDP gait training on executive control. The task used to assess this was the Wisconsin Card Sorting Task (WCST; Berg, 1948). Findings show increased activation in the pre-frontal cortex during completion of the WCST, consistent with this being a measure of executive functioning (e.g. Buchsbaum, Greer, Chang, \& Berman, 2005; Lie et al., 2006; Monchi, Petrides, Petre, Worsley, \& Dagher, 2001). In the task participants are presented with cards and asked to sort each card according to one of several rules. 
Initially they must use trial and error to find the correct rule, however once this is found they must continue to sort subsequent cards according to this rule. At random intervals the rule changes, requiring the adoption of a new rule and the inhibition of the old rule. Whilst there is some argument regarding which aspects of executive functioning the WCST measures, the task is an established measure of cognitive control and flexibility. An individual must "maintain" the correct attentional set to sort the cards accurately, however when the rule changes they must "flexibly" switch to a new set and inhibit the old (previously relevant) set. A number of measures can be taken from the WCST, one of the most important being perseverative errors (these occur when individuals continue to use the previously-relevant set and reflect the inability to flexibly change set and inhibit the old set).

The aim of this research study is to investigate the effects of QDP gait movement training on both joint repositioning and cognition in a healthy adult population. It was predicted that QDP training would improve performance in cognitive flexibility in the training group as determined by reduced perseverative errors in the WCST. It was further predicted that QDP training would result in improvements in joint reposition sense.

\section{Methodology}

\subsection{Participants}

Twenty-two healthy and physically active physical education students (15 male, 7 female) participated in this study and were randomly allocated into a training group (TG; n=11; Age $23 \pm 3.4$ years; Body Mass $75 \pm 18.7 \mathrm{Kg}$; Height $173.3 .3 \pm 10 \mathrm{~cm})$ and a control group $(\mathrm{CG}$; $\mathrm{n}=11$; Age $21.1 \pm$ 1.9 years; Body Mass $69.1 \pm 10.9 \mathrm{~kg}$; Height $172 \pm 7.8$ ). Participants were all degree level students, and had no shoulder or recent injuries that could interfere with the intervention. They also needed to 
take part in physical activity at least three times per week. Ethical approval was sought and gained from the College Ethical Approval Panel (Approval number 1314-258).

\subsection{Study design}

This was an independent measures study design where a control group (CG) and an experimental training group (TG) completed tests for cognitive control and joint reposition sense before and after a four-week intervention.

Executive control was measured using a computerised version of the WCST available through the Psychology Experiment Building Language (PEBL; Mueller, 2014; Mueller \& Piper, 2014). The whole test took approximately 15-20 minutes to complete. The programme provides several performance measures, however in the current study the measures used were conceptual level response (to provide an overall measure of success in the task; CLR), perseverative errors (PE), and non-perseverative errors (NPE).

To test joint repositioning, the participants were blindfolded and told to position their shoulder in 90-degree flexion, with their arm held immediately in front of them, parallel to the ground. From this starting position participants were moved a further 20 degrees into shoulder flexion (20F), where they held this for three seconds before being returned to the starting position. They were then instructed to actively reposition their shoulders to the $20 \mathrm{~F}$ position. A goniometer was used to determine the angles. Once they had completed this, the process was repeated for 30degrees of extension (30E) (Rogol, Ernst, \& Perrin, 1998). Tests were repeated a further two times for each angle. The error was defined as the difference between the original angle $(20 \mathrm{~F}$ or $30 \mathrm{E})$ and the angle achieved on repositioning the limb. Once all three errors had been calculated for each angle, the mean was determined for analysis.

During the four-week study period, the TG underwent a QDP training regimen three times a week, where they were taught a variety of closed chain support exercises involving forwards, 
backwards and sideway movements (Figure 1). Training sessions took place once a week for four consecutive weeks, with two additional sessions to complete at home. Instructed sessions lasted for an hour. The first 10 minutes of the session consisted of warming up and mobilising the participants. Then the next 50 minutes were used for teaching the basic movements and series of QDP locomotive sequences. During the four-week study period, both groups continued to engage in their normal physical activity levels (exercising at least three times per week).

(Figure 1 here)

\subsection{Data analysis}

Statistical analyses were carried out using Statistical Package for the Social Sciences (SPSS) version 20.0. To analyse performance in the WCST three dependent variables were selected. Percentage conceptual level response (CLR) was used to measure success and accuracy in the task, perseverative errors (PE) were used to measure an inability to switch set, and non-perseverative errors (NPE) were used to measure inaccurate responses not due to perseveration. Each variable was analysed using a 2 (group) x 2 (time) mixed measures ANOVA and partial eta squared was used to provide a measure of effect size. Three participants were removed on the basis that their scores were more than 2 standard deviations from the mean.

Although the main focus of the research was to explore the impact of a challenging, quadrupedal gait training movement system on cognition, it was important to assess any effects of training on joint reposition. To analyse this, the mean angle error made in repositioning a limb was calculated at $20 \mathrm{~F}$ and $30 \mathrm{E}$. Errors were compared for each group (training and control) between the first test and the final test using a paired samples t-test. 


\section{Results}

\subsection{Cognitive Control}

For CLR there was a significant effect of time, $F(1,17)=34.509, M S E=17.929, p<.001, \eta^{2}=.670$, with performance improving over time (means of $74.15 \%$ in the pre-test and $82.83 \%$ in the post-test). However, a significant interaction between time and group revealed that this improvement was only found for the TG $(70.25 \%$ vs. $85.65 \%)$ and not for the CG $(78.05 \%$ vs. $80.01 \%), F(1,17)=20.675$, $M S E=17.929, p<.001, \eta^{2}=.549$ (see figure 2). There was a non-significant effect of group, $F(1$, 17) $=0.373, M S E=25.522, p=.549, \eta^{2}=.021$.

(Figure 2 here)

Analysis of PE also showed a significant effect of time, $F(1,17)=9.291, M S E=11.839, p<$ $.01, \eta^{2}=.353$, with a reduction in errors from pre-test to post-test (15.22 vs. 11.56). There was also a significant time by group interaction, $F(1,17)=8.527, M S E=11.839, \eta^{2}=.334, p<.05$. This showed that whilst the number of PE reduced for the TG (16.83 vs. 9.67) the same benefit was not shown by the CG (13.62 vs. 13.46), see figure 3). The overall difference between the control and training groups was non-significant, $F(1,17)=0.052, M S E=13.248, p=.823, \eta^{2}=.003$.

(Figure 3 here)

Finally, analysis of NPE showed a similar pattern of performance. There was a significant effect of time, $F(1,17)=16.536, M S E=8.110, p<.01, \eta^{2}=.493$, and a significant interaction between time and group, $F(1,17)=4.558, M S E=8.110, p<.05, \eta^{2}=.211$. The number of NPE errors reduced from the first test to the second (8.81 vs. 4.77), however whilst there was a large 
reduction in errors following training for the TG (10.17 vs. 4.00) the difference between the first and second test was marginal for the CG (7.46 vs. 5.54), see figure 4. As above, there was no significant difference between the two groups for overall NPE in the task, $F(1,17)=0.265, M S E=10.554, p=$ $.614, \eta^{2}=.015$.

(Figure 4 here)

\subsection{Joint Repositioning}

For the TG, participants showed a significant improvement at 20F following the gait training programme, $t(7)=2.366, p=.05$ (mean errors of 4.13 and 2.13 for pre and post-training), see figure 5. There was no significant difference in errors at $30 \mathrm{E}$ (5.13 vs. 4.50). For the CG, performance did not vary across the time period for both $20 \mathrm{~F}$ (5.29 vs. 5.29) and $30 \mathrm{E}$ (5.21 vs. 5.50).

(Figure 5 here)

\section{Discussion}

The aim of the study was to explore the influence of a novel, QDP gait training programme on cognitive control. Participants were randomly allocated to two groups, a control group and a training group. All participants completed the WCST (a measure of cognitive control) at the beginning of the study and then four weeks later. Joint repositioning sense for $20 \mathrm{~F}$ and $30 \mathrm{E}$ was also assessed at these two time points. During the four-week period the training group also took part in the QDP gait training programme, consisting of a one hour supervised session and two at-home sessions per week. Following the introduction of a four-week QDP gait-training programme, the training group showed 
improved performance in the WCST, an effect that was not found for the control group. The WCST is a cognitive test designed to measure executive functions. The current findings show that the QDP training programme resulted in reduced perseverative errors suggesting that participants were better able to switch set when required. The training programme also led to a decrease in non-perseverative errors and an increase in the number of consecutive correct responses, showing that participants were better able to maintain a set. It can therefore be concluded that the training programme has had a short-term beneficial impact on cognitive control.

With regard to joint repositioning performance, the results provided support for the hypothesis that QDP will have a positive impact on errors in reposition sense. It is interesting that the study group showed improvements at $20 \mathrm{~F}$ and not at $30 \mathrm{E}$. This could be due to the specificity of adaptation to the common joint positions found in QDP, namely that 20 degrees of shoulder flexion represents the typical joint angle experienced when reaching forwards just prior to load bearing during QDP. This is consistent with previous findings (Rogol et al., 1998).

The significant improvements observed in the training group in the WCST raise some interesting issues. One possible explanation is that the training of the novel, complex, challenging task requires a degree of attentional discipline that improves over time and is then transferrable to other cognitive tasks. It is also possible that 'experience-induced brain plasticity' (Markham \& Greenough, 2004), the concept that animals placed in a complex learning environment will cognitively adjust as a result of the learning experience, also partially explains the findings. The fact that the control group, who also exercised at least three-times per week, failed to show significant improvements, may indicate that the observed changes are due to the type of exercise carried out, not the presence of exercise itself. In this case the training group undertook a novel, complex, challenging, and progressive training programme that, in many ways, mimics the dance interventions previously associated with positive cognitive outcomes (Hui et al., 2009; Kullberg-Turtiainen, 2012; Ravelin et al., 2013; Verghese et al., 2003). It should however be noted that whilst the QDP gait 
training programme shares similarities with dance and other coordination related activities, there are also key differences. In particular, the current training occurs without the presence of music and is less rhythmic. Some of the improvements in cognitive performance related to dance could be attributed to the fact that music may also be a motivator and may help to enhance positive emotions associated with neurological rehabilitation (Kattenstroth et al. 2013). This shows that improvements in cognitive function can still occur without the presence of music and without a focus on rhythmic movements. It also suggests that if the training programme were to include these aspects the cognitive benefits could be enhanced.

The quadrupedal movement undertaken by the training group required a great deal of route planning and remembrance of patterns, and the region of the brain that mediates these functions is the frontal lobe. Other frontal lobe functions include problem solving, working memory, cognitive flexibility, planning, movement initiation, and spatial orientation (Milner, 1964; Semmes et al., 1963). Whilst the WCST may not be exclusively dependent upon, and specific to, the frontal lobe, with prefrontal, frontal, temporal, parieto-temporal, and parieto-occipital cortical regions all activated during various stages of WCST performance (Monchi et al., 2001; Nyhus \& Braceló, 2009), it does appear that the frontal lobe plays a major role in cognitive control (Berman et al., 1995; Cabeza \& Nyberg, 2000; Konishi et al., 1998). The frontal lobe (specifically the premotor cortex) and the caudate nucleus are also responsible for accurate limb positioning. It is conceivable, therefore, that the challenge of learning a novel and challenging new motor skill such as QDP stimulates the same brain regions responsible for the areas of executive function that are directly involved when completing the WCST.

In the current study, it is unknown exactly when the benefits of the training occurred. In particular, whether improvements were larger during the initial, more novel and unfamiliar stages of the task (Bell \& Fox 1996) and then tailed off, or whether the progressive nature of the training resulted in a more consistent improvement throughout. Previous studies investigating the effect of 
motor learning training have reported both rapid changes in brain structure, especially in parietal and motor areas, within the first 7-14 days, but also more consistent improvements over a longer period (Driemeyer, Boyke, Gaser, Buschel, \& May, 2008; Taubert et al., 2010). It is also unknown how persistent or reversible these changes may be. Past studies have observed changes lasting for 4 weeks (Scholz, Klein, Behrens, \& Johansen-Berg, 2009), but also indications that such changes may be susceptible to reversal after 8-16 weeks (Draganski et al., 2004; Driemeyer et al., 2008). The authors recognise that at present we do not know whether any improvements may be long lasting. Further research is necessary to measure the exact benefits of QDP over time.

Future research would also be beneficial to establish the different constraints on any cognitive improvements. The current findings showed an interesting pattern of results across the three measures of the WCST with performance on the initial test lower for the TG compared to the CG. For instance, with perseverative errors, performance at pre-training for the TG was $16.83 \%$ and performance at pre-training for the CG was $13.62 \%$. It may be proposed that when performance on the task is poor initially there may be more scope for improvement, potentially suggesting that the improvement may not be entirely dependent upon the training. This could only be explored using a larger sample size and controlling for a number of factors that have been shown to influence executive function such as age (e.g. Rhodes, 2004). However, a recent study by Nouchi, et al. (2013) that investigated the effects of brain training games on a variety of cognitive measures found significant improvements in the WCST when pre-training performance was comparable to the current CG group (reported percentage of perseverative errors was $13.69 \%$ and $14.60 \%$ in two brain training groups). It may therefore be argued that the QDP training can have a beneficial impact on executive function regardless of initial cognitive ability.

With the significant results observed in a young, cognitively healthy population, the possibility exists that a similar intervention may have beneficial effects in other populations, such as an elderly population showing cognitive decline. It appears that dementia responds well to other 
interventions, with positive cognitive changes in dementia patients associated with physical exercise, particularly activities that prompt creativity (Hokkanen, Rantala, Remes, Harkonen, Viramo, \& Winblad, 2008; Hui et al., 2009; Kullberg-Turtiainen, 2012; Ravelin et al., 2013). It would be interesting to explore whether the same benefits can come from a QDP training programme and how these compare to those attributed to other forms of physical activity.

\section{Conclusion}

This is one of the first studies investigating the effects of QDP locomotion on cognition and joint repositioning. Results indicate that a novel and challenging quadrupedal gait training programme produced significant improvements to both joint reposition sense and cognitive control within a fourweek time frame. More investigation is required to determine how the benefits of QDP vary over time, yet it offers a further method for improving cognitive performance.

\section{References}

Ahlskog, J. E., Geda, Y. E., Graff-Radford, N. R., \& Petersen, R. C. (2011). Physical exercise as a preventive or disease-modifying treatment of dementia and brain aging. Mayo Clinic Proceedings, 86 (9), 876-884.

Anderson, P. J. (2008). Towards a developmental model of executive function. In V. Anderson, R. Jacobs, \& P. J. Anderson (Eds.), Executive Function and the frontal lobes: A lifespan perspective (pp. 3-21). New York: Taylor \& Francis. 
Behrer, L., Kramer, A. F., Peterson, M. S., Colcombe, S., Erickson, K., \& Becic, E. (2006). Testing the limits of cognitive plasticity in older adults: Application to attentional control. Acta Psychologica, 123, 261-278.

Bell, M. A. \& Fox, N. A. (1996). Crawling experience is related to changes in cortical organization during infancy: Evidence from EEG coherence. Developmental Psychobiology, 29 (7), 551561.

Berg, E. A. (1948). A simple objective technique for measuring flexibility in thinking. Journal of General Psychology, 39, 15-22.

Berman, K. F., Ostrem, J. L., Randolph, C., Gold, J., Goldberg, T. E., Coppola, R., .. Weinberger, D. R. (1995). Physiological activation of a cortical network during performance of the Wisconsin Card Sorting Test: a positron emission tomography study. Neuropsychologia, 33 (8), 1027-1046.

Buchman, A. S., Boyle, P. A., Yu, L., Shah, R. C., Wilson, R. S., Bennett, D. A. (2012). Total daily physical activity and the risk of AD and cognitive decline in older adults. Neurology, 24, $1323-1329$.

Buchsbaum, B. R., Greer, S., Chang, W., \& Berman, K. F. (2005). Meta-analysis of neuroimaging studies of the Wisconsin Card-Sorting Task and component processes. Human Brain Mapping, 25, 35-45.

Bunce, D.J., Barrowclough, A. \& Morris, I. (1996). The moderating influence of physical fitness on age gradients in vigilance and serial choice responding. Psychology and Aging, 11, 671-682.

Cabeza, R. \& Nyberg, L. (2000). Imaging cognition II: An empirical review of 275 PET and fMRI studies. Journal of Cognitive Neuroscience, 12 (1), 1-47.

Casey, B., Thomas, K., Welsh, T., Badgaiyan, R., Eccard, C., Jennings, J., \& Crone, E. (2000). Dissociation of response conflict, attentional selection, and expectancy with functional 
magnetic resonance imaging. Proceedings of the National Academy of Sciences of the United States of America, 97, 8728-8733.

Clearfield, M. W. (2004). The role of crawling and walking experience in infant spatial memory. Journal of Experimental Child Psychology, 89 (3), 214-241.

Colcombe, S. \& Kramer, A. F (2003). Fitness effects on the cognitive function of older adults: A meta-analytic study. Psychological Science, 14 (2), 125-130.

Colcombe, S. J., Kramer, A. F., Erickson, K. I., Scalf, P., McAuley, E., Cohen, N. J., ... Elavsky, S. (2004). Cardiovascular fitness, cortical plasticity, and aging. Proceedings of the National Academy of Sciences of the United States of America, 101, 3316-3321.

Cook, N., Albert, M., Berkman, L., Blazer, D., Taylor, J. \& Hennekens, C. (1995). Interrelationships of peak expiratory flow rate with physical and cognitive function in the elderly: MacArthur foundation studies of aging. Journal of Gerontology: Medical Sciences, 50, 317-323.

Daly, M., McMinn, D., \& Allan, J. L. (2015). A bidirectional relationship between physical activity and executive function in older adults. Frontiers in Human Neuroscience, 8 (1044), 1-9. doi: 10.3389/fnhum.2014.01044.

Diamond, A. (2013). Executive functions. Annual Review of Psychology, 64, 135-168. doi: 10.1146/annurev-psych-113011-143750.

Dietz, V. (2011). Quadrupedal coordination of bipedal gait: implications for movement disorders. Journal of Neurology, 258, 1406-1412.

Draganski, B., Gaser, C., Busch, V., Schuierer, G., Bogdahn, U., \& May, A. (2004). Neuroplasticity: changes in grey matter induced by training. Nature, 427, 311-312.

Driemeyer, J., Boyke, J., Gaser, C., Buchel, C., \& May, A. (2008). Changes in gray matter induced by learning - revisited. PLoS One, 3, e2669. doi: 10.1371/journal.pone.0002669. 
Erickson, K. I., Voss, M. W., Prakash, R. S., Basak, C., Szabo, A., Chaddock, L., ... Kramer, A. F. (2011). Exercise training increases size of hippocampus and improves memory. Proceedings of the National Academy of Sciences of the United States of America, 108 (7), 3017-3022. doi: 10.1073/pnas.1015950108.

Firth, J., Cotter, J., Elliott, R., French, P., \& Yung, A. R. (2015). A systematic review and metaanalysis of exercise interventions in schizophrenia patients. Psychological Medicine, 45 (7), 1343-1361.

Ford, E. S. (2002). Does exercise reduce inflammation? Physical activity and C-reactive protein among US adults. Epidemiology, 13 (5), 561-568.

Freedland, R. L. \& Bertenthal, B. I. (1994). Developmental changes in interlimb coordination: Transition to hands-and-knees crawling. Psychological Science, 5 (1), 26-32.

Gleeson, M., McDonald, W. A., Cripps, A. W., Pyne, D. B., Clancy, R. L., \& Fricker, P. A. (1995). The effect on immunity of long- term intensive training in elite swimmers. Clinical \& Experimental Immunology, 102 (1), 210-216.

Gligoroska, J. P. \& Manchevska, S. (2012). The effect of physical activity on cognition physiological mechanisms. Materia Socio-Medica, 24, 198-202.

Hamer, M. \& Chida, Y. (2009). Physical activity and risk of neurodegenerative disease: a systematic review of prospective evidence. Psychological Medicine, 39 (01), 3-11.

Herbert, J., Gross, J., \& Hayne, H. (2007). Crawling is associated with more flexible memory retrieval by 9- month- old infants. Developmental Science, 10 (2), 183-189.

Hillman, C. H., Erickson, K. I., \& Kramer, A. F. (2008). Be smart, exercise your heart: exercise effects on brain and cognition. Nature Reviews Neuroscience, 9, 58-65.

Hillman, C. H., Motl, R. W., Pontifex, M. B., Posthuma, D., Stubbe, J. H., Boomsma, D. I. \& De Geus, E. J. (2006). Physical activity and cognitive function in a cross-section of younger and older community dwelling individuals. Health Psychology, 25 (6), 678-687. 
Hoffinan- Goetz, L. (1998). Influence of physical activity and exercise on innate immunity. Nutrition Reviews, 56 (1), S126-S130.

Hokkanen, L., Rantala, L., Remes, A. M., Harkonen, B., Viramo, P., \& Winblad, I. (2008). Dance and movement therapeutic methods in management of dementia: a randomized, controlled study. Journal of the American Geriatrics Society, 56 (4), 771-772.

Hui, E., Chui, B. T. K. \& Woo, J. (2009). Effects of dance on physical and psychological well-being in older persons. Archives of Gerontology and Geriatrics, 49 (1), 45-50.

Kattenstroth, J. C., Kalisch, T., Holt, S., Tegenthoff, M., \& Dinse, H. R. (2013). Six months of dance intervention enhances postural, sensorimotor, and cognitive performance in elderly without affecting cardio-respiratory functions. Frontiers in Aging Neuroscience, 5 (5), 1-16. doi: 10.3389/fnagi.2013.00005.

Kermoian, R. \& Campos, J. J. (1988). Locomotor experience: A facilitator of spatial cognitive development. Child Development, 59 (4), 908-917.

Kim, C., Cilles, S. E., Johnson, N. F., Gold, B. T. (2012). Domain general and domain preferential brain regions associated with different types of task switching: a meta-analysis. Human Brain Mapping, 33, 130-142.

Kondo, S. (1985). Primate morphophysiology, locomotor analyses and human bipedalism. American Journal of Physical Anthropology, 70 (2), 278-279.

Konishi, S., Nakajima, K., Uchida, I., Kameyama, M., Nakahara, K., Sekihara, K. \& Miyashita, Y. (1998). Transient activation of inferior prefrontal cortex during cognitive set shifting. Nature Neuroscience, 1 (1), 80-84.

Kullberg-Turtiainen, M. (2012). The effects of dancing on the brain and possibilities as a form of rehabilitation in severe brain injuries. Duodecim; Laaketieteellinen Aikakauskirja, 129 (20), 2141-2447. 
Lamb, S. E., Jørstad- Stein, E. C., Hauer, K. \& Becker, C. (2005). Development of a common outcome data set for fall injury prevention trials: The Prevention of Falls Network Europe Consensus. Journal of the American Geriatrics Society, 53 (9), 1618-1622.

Lie, C., Specht, K., Marshall, J., \& Fink, G. (2006). Using fMRI to decompose the neural processes underlying the Wisconsin Card Sorting Test. NeuroImage, 30, 1038-1049.

Mann, D. T. Y., Williams, A. M., Ward, P., \& Janelle, C. M. (2007). Perceptual-cognitive expertise in sport: A meta-analysis. Journal of Sport \& Exercise Psychology, 29, 457-478.

Markham, J. A. \& Greenough, W. T. (2004). Experience-driven brain plasticity: beyond the synapse. Neuron Glia Biology 1 (4), 351-363.

McAuliffe, J. (2004). Differences in attentional set between athletes and nonathletes. The Journal of General Psychology, 131 (4), 426-437.

McAuley, E., Mullen, S. P., Szabo, A. N., White, S. M., Wojcicki, T. R., Mailey, E. L. ... Kramer, A. F. (2011). American Journal of Preventive Medicine, 41 (3), 284-290. doi: 10.1016/j.amepre.2011.04.014.

Mcewan, M. H., Dihoff, R. E., \& Brosvic, G. M. (1991). Early infant crawling experience is reflected in later motor skill development. Perceptual and motor skills. Perceptual and Motor Skills, 72 (1), 75-79.

Milner, B. (1964). Some effects of frontal lobectomy in man. In J. M. Warren \& K. Akert (Eds.), The frontal granular cortex and behavior (pp.313-334). New York: McGraw-Hill.

Monchi, O., Petrides, M., Petre, V., Worsley, K., \& Dagher, A. I. (2001). Wisconsin Card Sorting Revisited: Distinct Neural Circuits Participating in Different Stages of the Task Identified by Event-Related Functional Magnetic Resonance Imaging. Journal of Neuroscience, 21 (19), 7733-7741.

Monno, A., Temprado, J. J., Zanone, P. G., \& Laurent, M. (2002). The interplay of attention and bimanual coordination dynamics. Acta Psychologica, 110, 187-211. 
Mueller, S. T. (2014). PEBL: The Psychology experiment building language (Version 0.14) [Computer experiment programming language]. Retrieved September 2014 from http://pebl.sourceforge.net.

Mueller, S. T. \& Piper, B. J. (2014). The Psychology Experiment Building Language (PEBL) and PEBL Test Battery. Journal of Neuroscience Methods, 222, 250-259.

Nouchi, R., Taki, Y., Takeuchi, H., Hasgizume, H., Nozawa, T., Kambara, T., ... Kawashima, R. (2013). Brain training game boosts executive functions, working memory, and procedding speed in the young adults: A randomized controlled trial. PLoS ONE 8 (2), e55518. doi: 10.1371/journal.pone.oo55518.

Nuernberger, P., Rogers, T., \& Mckenna, L. (2010). The B-K Everyday. Celebrating Every Learner: Activities and Strategies for Creating a Multiple Intelligences Classroom, (77-78). United states of America: Wiley.

Nyhus, E. \& Barceló, F. (2009). The Wisconsin Card Sorting Test and the cognitive assessment of prefrontal executive functions: A critical update. Brain and Cognition, 71 (3), 437-451.

Owen, A. M., Roberts, A. C., Hodges, J. R., Summers, B. A., Polkey, C. E., \& Robbins, T. W. (1993). Contrasting mechanisms of impaired attentional set-shifting in patients with frontal lobe damage or Parkinson's disease. Brain, 116, 1159-1175.

Pahor, M. (2006). Effects of a physical activity intervention on measures of physical performance: results of the Lifestyle Interventions and Independence for Elders Pilot (LIFE-P) study. The Journals of Gerontology: Series A: Biological Sciences and Medical Sciences. 62 (3), 11571165.

Paillard, T. (2015). Preventive effects of regular physical exercise against cognitive decline and the risk of dementia with age advancement. Sports Medicine - Open, 1 (20), 1-6. doi: 10.1186/s40798-015-0016-x. 
Patrick, S. K., Noah, J. A., \& Yang, J. F. (2009). Interlimb coordination in human crawling reveals similarities in development and neural control with quadrupeds. Journal of Neurophysiology, 101 (2), 603-613.

Piek, J. P., Dawson, L., Smith, L. M., \& Gasson, N. (2008). The role of early fine and gross motor development on later motor and cognitive ability. Human Movement Science, 27 (5), 668681.

Ravelin, T., Isola, A., \& Kylmä, J. (2013). Dance performance as a method of intervention as experienced by older persons with dementia. International Journal of Older Person Nursing, 8 (1), 10-18.

Rhodes, M. G. (2004). Age-related differences in performance on the Wisconsin Card Sorting Test: A meta-analytic review. Psychology and Aging, 19 (3), 482-494.

Rogol, I. M., Ernst, G., \& Perrin, D. H. (1998). Open and closed kinetic chain exercises improve shoulder joint reposition sense equally in healthy subjects. Journal of Athletic Training, 33 (4), 315-318.

Scherder, E. J., Bogen, T., Eggermont, L. H., Hamers, J. P., \& Swaab, D. F. (2010). The more physical inactivity, the more agitation in dementia. International Psychgeriatrics, 22 (8), 1203-1208.

Scholz, J., Klein, M. C., Behrens, T. E., \& Johansen-Berg, H. (2009). Training induces changes in white-matter architecture. Nature Neuroscience, 12, 1370-1371.

Sehm, B., Taubert, M., Conde, V., Weise, D., Classen, J., Dukart, J., Draganski, B., Villringer, A., \& Ragert, P. (2014). Structural brain plasticity in Parkinson's disease induced by balance training. Neurobiology of Aging, 35 (1), 232-239.

Semmes, J., Weinstein, S., Ghent, L., Meyer, J. S., \& Teuber, H. (1963). Impaired orientation in personal and extrapersonal space. Brain, 86, 747-772. 
Shah, P. K., Garcia-Alias, G., Choe, J., Gad, P. Gerasimenko, Y., Tillakaratne, N., ... Edgerton, V. R. (2013). Use of quadrupedal step training to re-engage spinal interneuronal networks and improve locomotor function after spinal cord injury. Brain, 136, (12), 3362-3377.

Tanaka, K., de Quadros, A. C., Santos, R. F., Stella, F., Gobbi, L. T. B., \& Gobbi, S. (2009). Benefits of physical exercise on executive functions in older people with Parkinson's disease. Brain and Cognition, 69 (2), 435-441.

Taubert, M., Draganski, B., Anwander, A., Muller, K., Horstmann, A., Villringer, A., \& Ragert, P. (2010). Dynamic properties of human brain structure: learning-related changes in cortical areas and associated fiber connections. The Journal of Neuroscience, 30, 11670-11677.

Venkatraman, J. T., \& Fernandes, G. (1997). Exercise, immunity and aging. Aging Clinical and Experimental Research, 9 (1-2), 42-56.

Verghese, J., Lipton, R. B., Katz, M. J., Hall, C. B., Derby, C. A., Kuslansky, G., \& Buschke, H. (2003). Leisure activities and the risk of dementia in the elderly. The New England Journal of Medicine, 348, 2508-2516.

Voelcker-Rehage, C., Godde, B., Staudinger, U. M. (2011). Cardiovascular and coordination training differentially improve cognitive performance and neural processing in older adults. Frontiers in Human Neuroscience, 5 (26), 1-12. doi:10.3389/fnhum.2011.00026.

Voelcker-Rehage, C. \& Niemann, C. (2013). Structural and functional brain changes related to different types of physical activity across the life span. Neuroscience and Biobehavioural Reviews, 37, 2268-2295.

Voss, M. W., Kramer, A. F., Basak, C., Prakash, R. S., \& Roberts, B. (2010). Are expert athletes 'expert' in the cognitive laboratory? A meta-analytic review of cognition and sport exercise. Applied Cognitive Psychology, 24 (6), 812-826.

Woods, J. A., Vieira, V. J., \& Keylock, K. T. (2009). Exercise, inflammation, and innate immunity. Neurologic Clinics, 29 (2), 381-393. 
Zelazo, P., Craik, F., \& Booth, L. (2004). Executive function across the life span. Acta Psychologica, 115 (2-3), 167-183. 